\title{
Re-Configuring Agnes: The Telling of a Transsexual's Story
}

\section{REBECCA C. RABY}

Rebecca Raby's research interests include social and sociological theory, responsible pedagogy, constructions of age and aging, social/ moral regulation, and social change. She is currently completing her dissertation in sociology at York University. Responses may be sent to her bye-mail at rraby@yorku.ca.

To be differently-gendered is to live within a discourse where other people are always investigating you, describing you, speaking for you; and putting as much

distance as possible between the expert speaker and the deviant and therefore deficient subject.

- Pat Califia (2)

I

$\mathrm{n}$ the social sciences, researchers, interviewers, and narrators of peoples' experiences present selective recordings of subjects' voices. This paper concentrates on the portrayal of transsexual narratives - with a particular focus on representations of one subject, Agnes - as they have been selectively constituted by social scientists. Agnes, a transsexual, participated in Harold Garfinkel's research in the late 1960s, making her the first subject of an in-depth discussion of transsexuality in sociology. I contend that a number of social scientists scrutinize and evaluate Agnes's and other transsexuals' narratives for 'truth', and frame transsexuality as a window into gender construction. At the same time, however, these social scientists mold Agnes's identity to illustrate particular theoretical positions and avoid examining their own investments in their subjects. As well, they neglect to consider their own ongoing reproductions of hegemonic gender relations. In this paper, I explore how social scientists might selectively record subjects' voices while remaining self-reflexive and committed to the integrity of the interviewee.

torquere: Journal of the Canadian Lesbian and Gay Studies Association / Revue de la Société canadienne des études lesbiennes et gaies Vol. 2 (2000) @ CLGSA / SCELG 
First, I link the sociological fascination with Agnes to the discipline's interest in 'Other' sex and gender configurations, an interest that is frequently explored as a way to understand 'normal' gender arrangements in Western society. Second, I focus on how the example of Agnes is deployed, as social scientists both evaluate her self-narratives and unselfconsciously produce alternative 'Agneses' that exemplify their theoretical positions. Finally, I address ethical practice. Social scientists must recognize their investments in the examples they use. In particular, researchers need to identify and disrupt the Othering of research subjects by acknowledging everyone's implication in the production of gender. I conclude by arguing that while there is no 'true' construction of Agnes, there is a person behind the examples, with her own lived experiences, within a particular set of material and discursive conditions, who must be respected. However, my intention in addressing the above points is not necessarily to unveil the 'real' Agnes.

I too have investments in writing on this topic and these affect my own examination of the ways in which examples of Agnes are deployed. A sociologist by training, I hold deep-seated concerns with the discipline's need to categorize, to label, and to investigate the 'Other,' particularly when these practices are upheld by the epistemological premise of an objective, detached observer. As a result of these concerns, I am drawn to the flexibility of interdisciplinarity, and to a postmodern skepticism with the 'objectivity' and universalizing truth assertions of the social sciences. Examples are always invested. Thus, how we document and apply these examples is of great importance. I do not reject the potency of structured power relations, particularly since some groups and institutions - such as social science researchers within health care and educational institutions - have more authority than others in the production of discourse. These discourses in turn have material effects on people's lives. Transsexuals, as a marginal population, are particularly vulnerable to such effects. Finally, although not a transsexual, in trying to make sense of transsexuality and how it has been taken up in sociological texts, I draw on my own confrontations with the dichotomous and often rigid categories of gay and straight, butch and femme, and man and woman. 


\section{Visiting the Other}

This section will focus on sociology's use of 'Others' to understand the 'normal', with a particular emphasis on transsexuality and the study of gender. First, discourses sometimes use transsexual and transgender interchangeably. I focus on transsexualism since this is the primary concern of most of the texts under review. Transsexualism is defined as experiencing a lack of correspondence between one's sense of gender and one's anatomical sex, and a response to this situation that might include sex-change surgery. Those who experience a lack of correspondence between their sex and their gender but who are not interested in sex change, and many who affiliate with a wider 'trans' movement, may define themselves as transgendered.

Some sociologists, attempting to disrupt naturalized, 'commonsense' assumptions about Western cultural traditions, have employed spatial and temporal comparisons, particularly in terms of sex and gender. There is a tradition of feminist theorists using this comparative method to point to commonalities between cultures and to foreground divergences in cultural gender roles and sexual statuses (see esp. di Leonardo; Mead; Rubin; for discussion see Atkinson; Morris). Recently cross-cultural and cross-historical instances of 'homosexual' and 'transsexual' behaviors have been deployed in the name of sex-gender scholarship (see esp. Anderson; Kessler \& McKenna; Morris). Here, some anthropologists ethnocentrically build their own assumptions about gender into their analyses of other cultures. For example, Suzanne Kessler and Wendy McKenna maintain that anthropologists often interpret their observations of other cultures through the organizing concepts of their own. They expect to see two genders, each with an equivalent gender role, and therefore they do. In order to substantiate their claims, Kessler and McKenna point to literature on the berdache, a term that has been extended from North American Native cultures to many differently gendered social positions found in a number of cultures. They criticize the tendency in such literature to misdefine the berdache. For example, the terms 'transsexual' or 'hermaphrodite' are used to describe the berdache, and traits linked to the berdache are overgeneralized across cultures (see esp. Bolin; Califia). In her article "Gender: Division or Comparison?" Marilyn Strathern explores several fundamentally different cultural conceptions of gender, conceptions that complicate attempts to identify any transcultural constructions of gender. The ethnocentric search for 'other' 
transsexuals presupposes that different cultures can be understood through Western categories and systems of knowledge.

Similarly, 'unusual' or 'deviant' persons and groups within Western society have attracted attention from generations of social scientists - as disruptions of cultural assumptions and testaments to human diversity. Robert K. Merton's article on anomie, Erving Goffman's Stigma, and Harold Garfinkel's essay on Agnes are three prominent sociological works that seek large scale social understanding by studying local, 'marginal' people. Social scientific interest in transsexualism and transgenderism often reflects this tradition of studying 'anomalies' (see Garfinkel; Hausman) based on the argument that "it is by studying how exceptions are accommodated that we can best understand the nonexceptional cases" (Kessler \& McKenna 23).

Unfortunately, these studies often frame the 'Other' as essentially different from, and inferior to, its 'normal' opposite (see Garfinkel; Hausman). The sociology of deviance, for example, despite some attention to the social construction and labeling of deviance (see Rubington and Weinberg, and Schissel and Mahood for edited collections), often remains voyeuristic and framed in the interests of social control (particularly when linked to criminology). Alexander Liazos's charge that it tends to reproduce presumed categories of 'normal' and 'deviant' while ignoring the power relations behind these designations continues to be applicable today, particularly in that the life of the 'deviant' receives far more attention than questions regarding how 'normal' is defined, who designates the 'other', and what is at stake in these definitions. Transsexuality, of course, does not remain unscathed.

These concerns are not limited to the field of the sociology of deviance. Queer theory also draws on transsexuality, adopting it, with transgenderism, as "a queer transgressive force" (Prosser 23). Jay Prosser argues that such an appropriation is problematic since first, transgenderism is not inherently queer - for example, Prosser states, not all transgendered people are homosexual and many of them seek not to be performative, but simply to be-and second, because it implies a "naturalness of sex" for the nontransgendered. Ki Namaste is also critical of queer theory - and Judith Butler's work in particular - for overemphasizing textual meanings and ignoring the material or lived realities of transsexual and transgendered people. Namaste looks to 


\section{2 / Raby}

the social sciences for preferred methodology, particularly the works of ethnomethodologists Harold Garfinkel, and Susanne Kessler and Wendy McKenna, who are reexamined here. Like Namaste, I am concerned with research that undermines "the lives and experiences of the transgendered people they study" (185), but as my following discussion of Agnes suggests, I do not see social science methodologies as immune to this tendency.

\section{Introducing Agnes}

A large chapter of Garfinkel's Studies in Ethnomethodology is devoted to Agnes, a transsexual woman who was introduced to Garfinkel by Dr. Robert Stoller, the physician who documented and supervised treatment. While Stoller is most interested in the etiology and treatment of transsexuality, Garfinkel studies the methods Agnes uses to negotiate daily life.

According to Garfinkel, Agnes was born with male physical attributes and raised as male, yet all the while she knew herself to be female. When Garfinkel first met her, she had a penis and testicles in conjunction with secondary female characteristics such as breasts. At seventeen she began dressing and acting as the woman that she knew herself to be. She wanted to have the penis removed and replaced with a vagina. Garfinkel uses Agnes as an example for ethnomethodology. He examines the methods Agnes uses to pass as a woman, or to live successfully as a woman in a context in which there is "the possibility of detection and ruin" due to the "socially structured conditions" in which the passing occurs (Garfinkel 118). $\mathrm{He}$ is interested in Agnes's passing in order to examine the construction of gender and the methods individuals use to perform it. To him, Agnes's transsexualism is a mechanism through which the performance of 'normal' gender/sex can be understood. Garfinkel assumes that when a person undergoes a sex change, they must adjust to a new set of rules and behavioral expectations. To perform their new gender successfully, they must excel at the task of simultaneously learning and living a new gender. The energy that Agnes spent negotiating her own passing and appeasing her own fear of exposure illustrates the ubiquitous and threatening presence of gender as an institutionalized moral 'fact', a 'commonsense' notion that is taken for granted by 'normals,' considered the legitimate order, and policed through social sanctions. 
Garfinkel's Studies in Ethnomethodology includes an epilogue which reports that, five years after Garfinkel's research, Agnes approached Robert Stoller with a number of changes to her personal history. As we shall see below, these changes became a site of scrutiny.

Agnes's identity has been incorporated into literatures as diverse as ethnomethodology, feminism, queer theory, and social psychology. The remainder of this paper will focus on two interrelated themes. First, I consider how some researchers respond to Agnes's changing story, particularly as they are concerned with her truthfulness and self-fashioning (and the truthfulness and self-fashioning of other transsexuals). Second, I consider how the example of Agnes is produced by such researchers in pursuit of their own theoretical positions.

\section{Truth and Self-Fashioning}

To Garfinkel, Agnes's later disclosure was simply another example to illustrate how she used "rational accountability" (288) to bolster her practical accomplishments. When activities are organized in familiar, accountable ways, then they are accepted by others (including Garfinkel). Truthfulness (or not) is secondary. For the most part, Garfinkel seems to accept Agnes's accounts, asserting that for her to live her life as she does, she must lie. Yet despite his sympathies, Garfinkel's observations foreground Agnes's dissembling.

Garfinkel twice observes that "Her accounts exaggerated the evidences of her natural femininity and suppressed evidences of masculinity" (120). Later, he states that "she was a highly accomplished liar" (174). Further, he points out seven areas that Agnes would not discuss, including any interest in boys' activities when she was young, or her possible use of hormones prior to the research (implying Garfinkel's suspicions that she was hiding information). In an ironic twist, he also states: "She wanted to know as well whether [more research] would help 'the doctors' to get the 'true facts'. I asked Agnes, 'What do you figure the facts are?' She answered, 'what do I figure the facts are, or what do I think everyone else thinks the facts are?'" (175). Here Agnes is fully aware of the need to selffashion in the face of others' versions of what should be the truth.

Furthermore, Garfinkel notices that Agnes uses "anticipatory following" (147) in some of her discussions with him: he believes that she attempts to gather clues from him about what kind of answer 
he seeks in order to provide him with the information that she suspects he wishes to hear. Garfinkel is aware that he may be asking leading questions but does not seem able to acknowledge that those questions might also be constructed through his role in maintaining traditional dichotomous gender relations.

Is Garfinkel judging Agnes's truthfulness? He claims to be interested only in Agnes's strategies for learning femininity while living as a woman. A less charitable reading might dwell on the implications of foregrounding strategies which suggest that Agnes and other 'gender transgressors' must lie, when both the gendering of all self-narratives and the anticipatory following that everyone does tend to remain unexamined. Certainly, in his other work, Garfinkel is interested in people's methods for negotiating daily life in a number of areas. My point is that by foregrounding Agnes's need to dissemble as she performs gender, the invisibility of everyone else's gender dissembling, including Garfinkel's, may be deepened rather than lessened.

In fact, others are much more concerned with Agnes's 'true' story. Norman Denzin is obsessed with narrating the 'truth' and consequently presenting an Agnes who lies. In reporting her story, Denzin footnotes certain 'corrections' based on her later interviews with Stoller. For example, he states: "Now another lie appears in the text: she told Stoller that she did play with boys, was excellent in sports, and thought of herself as a boy" (206). Denzin thinks that Garfinkel was fooled by Agnes, because he refused to see beyond her story to consider the role of her "wild" sexuality. According to Denzin, Garfinkel thus misses the psychoanalytic reading that his work invites. I will return to Denzin's psychoanalytic reading in more detail below. In the meantime, Denzin's interest in Agnes's potential 'lies' and in how she "had duped the doctors and Garfinkel" (203) remains significant in that dishonesty or misrepresentation constitutes an established yet hardly flattering way in which to discuss transsexuals' self-narratives.

Bernice Hausman briefly discusses Agnes in the opening introduction of her monograph Changing Sex. She is interested in Agnes's need to present herself as a straight, feminine woman in order to convince medical personnel that she is in need of surgery. Later, in her chapter on three 'official' transsexual autobiographies, Hausman argues that transsexuals use gender 
to mask the role of technology in their subject formation. She suggests that transsexuals downplay their surgery and exaggerate childhood physical and psychological 'indicators' of their transsexualism. Hausman suggests that these autobiographies, in fact, produce transsexual experience, since they are then used to educate other transsexuals as to the appropriate life histories that must be constructed and then presented to medical allies in order to garner surgery. Hausman discusses such autobiographies as aggressive, and exhausting to read, because they "force the reader to comply with the author's experience, to begin to interpret his or her own life along the same trajectory" (156). Further, she accuses the authors of masking bodily resistances to sex-change surgery. While denying that she questions the truth behind these accounts - since she maintains that she is only showing how they are constructed within, and then produce, certain discourses Hausman does filter these autobiographies through a hostile lens that reflects her later concern with transsexual self-engineering (136-40).

While sociologist Douglas Mason-Schrock's study of transsexuals' self-narratives does not mention Agnes specifically, it does focus on how transsexuals fashion stories for themselves. He draws on his own observations - of a self-help group for transsexuals, transsexual chat groups on the Internet, and other Internet information sources. While recognizing that all people use self-narratives, he suggests that transsexuals need particularly strong self-narratives as they undergo a radical and stressful identity change. With this premise in mind, Mason-Schrock examines the process through which transsexuals fashion new stories for themselves, a process that involves coaching and guidance from the transsexual community.

Mason-Schrock considers these self-narratives "collective creations" (186). Self-narratives are modeled (e.g., through transgender community publications), guided (e.g., by drawing out newcomers' stories in transsexual groups), and affirmed (e.g., through "um-hums," nods, and smiles during group meetings). Tactful blindness also serves to shape self-narratives: group members "affirmed self-narratives by not questioning their validity or logical coherence" (189). Mason-Schrock observes transsexual self-narratives as examples of how all people frame 
their lives through narrative to structure a coherent self-identity. Nevertheless, again it is the creation of transsexuals' stories that gets attention. Mason-Schrock also neglects to contextualize the 'community coaching' to which he is a witness: transsexuals' narratives are formulated in a context where their bodily integrity requires that they be able to tell the 'proper,' narrowly defined, and rigorously scrutinized story to doctors, in order to garner hormones and surgery.

Jay Prosser also discusses transsexuals' autobiographies, although much more sympathetically, suggesting that they indicate agency through the capacity to self-represent. Prosser examines autobiography as a genre, not limited to transsexuals, that creates a coherent subject by reinterpreting the past. The narrative of the transsexual's life is key to defining transsexuality and accessing surgery. Of course, this archetype also censors other possible, legitimate, transsexual tales. Clinicians try to figure out whether a person is really transsexual, whether their stories are really true. So transsexuals must be convincing storytellers since they are evaluated for telling the 'right' story rather than narrating their personal experiences. Yet even beyond the clinician's office, Prosser argues, autobiography is indispensable as it makes the realization of transsexual subjectivity possible. For transsexuals, autobiographies provide a way to reconcile a coherent ' $I$ ' with a dramatically changing biography. Prosser stresses that his analysis does not invalidate transsexuals' gender narratives, for such narratives are the only way subjects - any subjects - can realize their categorical belonging (125). Autobiography also undoes the passing by uncovering the transsexual history that is hidden by surgery.

Garfinkel and others assume that Agnes, like other transsexuals, is more aware of the strictures of gender than are people who do not question their own sex or gender locations. To some observers, the gender awareness that Agnes is assumed to possess implies a loss of innocence, even a corruption, as she must consciously manipulate and occasionally 'lie' to maintain her appearance as a 'natural-born' woman. Thus, when Agnes is represented as having agency, she is at once read as a manipulative, untrustworthy agent (Hausman) or as being strong and self-defining (Prosser; Rogers). On the other hand, where she is said not to have agency, Agnes is framed as a "gender dupe" who reproduces traditional gender roles (Hausman) or as a 
victim who is painfully caught in the rules of dichotomous gender (Rogers). When truth, selfhood, and agency are considered, transsexuals are often perceived to be complicit with traditional gender norms, invested in self-presentation and guilty of medical tinkering. Certainly Agnes's and other transsexuals' narratives are subject to scrutiny. Those who feel more at home in their sexed bodies (a.k.a. Garfinkel's "normals"), while equally complicit, more easily elude designations of 'gender dupes' who have been fooled by gender norms, or 'gender cons' who are trying to dupe the rest of us, by virtue of the very presumption that they are 'normal' and of their socalled 'natural' embeddedness in 'commonsense' gender.

\section{Examples Are Never Innocent}

In the second part of this paper, I am concerned with how transsexuals, as research subjects, are figured in social science discourses. The use of case examples, such as interviews, in sociological writing (and this essay is no exception) is not objective or disinterested: theoretical, political, academic, and personal investments influence the presentation of data. I will examine articles by Garfinkel, by Denzin, and by Rogers to discuss how Agnes has been variously deployed as a textual figure in the interests of such investments.

I have already discussed Garfinkel's interest in Agnes as an example for ethnomethodology. He uses Agnes to show both the social embeddedness of everyday practices that produce 'normal' sexuality and the methods that Agnes uses to manage her claims of being a natural female. For, unlike 'normals,' Agnes had to consciously act as 'practical methodologist,' always being prepared to account for her actions.

Garfinkel's intention is to supply an example of ethnomethodology, and yet he seems oblivious to his own methods and to the wider power relations evident in his interviews. Like Richard Hilbert, Garfinkel might defend his chapter by saying that it is about Agnes's methods and not his own: "Ethnomethods are not ethnomethodology's research methods but rather its topic of investigation" (Hilbert 264). Yet Garfinkel and particularly his masculinity are evident throughout the paper, a fact that suggests a need for him to reflect upon his own gender performance. Typical of ethnomethodology, Garfinkel does not dwell on the power relations confronting Agnes, such as the institutional forces constraining Agnes's presentation of 


\section{8 / Raby}

self or his own implication in them. While Garfinkel's stated objective is to provide a sympathetic account showing how everyone must do gender, Agnes remains constructed by the text as a freak. This is supported by detailed biological information and by the occasional doubting of the subject's own words.

Candace West and Don Zimmerman expand on Garfinkel's work on ethnomethodology and gender and also use Agnes as an example to demonstrate that gender is always present in people, since it is constantly produced within everyday activities. Agnes had to learn to be a woman while being a woman, "at a time when most people's gender would be well-accredited and routinized" (131). They use the example of Agnes to indicate how, on a day-to-day basis, sex is signified through sex category, allowing us to determine people's sex based on surface appearances. Most people do not look rigorously for indicators of sex unless given some reason to doubt. For Agnes, as long as people saw a woman, they would not think to doubt. Yet to portray a 'normal woman' she had to modify and adjust her behavior constantly.

It is curious that Garfinkel, West and Zimmerman, and even Agnes place significant emphasis on the difficulties in performing woman when one has been raised a man - that is, treating femininity as different and detached from masculinity. Yet masculinity and femininity are relational positions. Much of what we learn about performing gender comes from the interactions between men and women. In fact, as far as Agnes is concerned, her boyfriend Bill provides her with just as much information about how to 'be a woman' as women do. Further, as C. Jacob Hale observes, 'woman' and 'man' are complicated since there are many ways of being men and women, and the borders between genders are blurry. These varied gender categories change as people age. They also change contextually. Certainly, Agnes has an added threat of exposure that most women do not have. And yet at the same time, doubt in one's femininity (or masculinity) does not suddenly end with the teen years. Parenthood, menopause, 'mid-life crises,' and old age are just a few of the more obvious periods in life causing possible gender anxiety. Perhaps if gender were examined with the assumption that most of us are worried about its accomplishment, a similar study could be conducted on anyone. In this event, Agnes would no longer seem so unusual.

Ironically, it is the deconstructionist Denzin whose assertions 
about "Harold and Agnes" are the most presumptuous. Drawing together French thinker Jacques Derrida's position that there is only text and Garfinkel's position that the "objective reality of social facts is accomplishment" (Garfinkel in Denzin 199), Denzin explores how texts become social accomplishments that can be deconstructed. Denzin critiques Garfinkel for failing to recognize the "radical turn" in his own work. Garfinkel accepts people's accounts of their activities as literal, and then interprets these accounts based on his understanding of underlying social patterns. While Garfinkel's text is a specific production of Agnes, Denzin's own interpretations tell an even more imaginative story.

First, Denzin asserts that Garfinkel oedipalizes his subject, regarding Garfinkel like a father (and sometimes even a mother) who leads Agnes into femininity. Denzin also considers Garfinkel in the position of Agnes's male other: "Garfinkel as author of his text has become one with his subject; they are mirror opposites of one another" (205). Denzin thus explains the way in which Garfinkel acquires the authority to tell Agnes's story, presuming that Garfinkel's "commonsense understandings of what Agnes did also constitute her commonsense understandings" (208).

Second, Denzin believes there to be a further psychoanalytic subtext (or "sexual underside") to Garfinkel's text that, according to Denzin, Garfinkel does not address even though it is his own creation. Garfinkel fails to "penetrate ... the world of [Agnes's] 'wild' sexuality" (209) as the earlier sociologist conflates sexuality and gender and, therefore, backs away from examining sexuality itself. This subtext is evident to Denzin in Agnes's "Strange Sexual Story" (210) in a number of ways: in the oedipal story structure underlying the text, in the importance of a sought castration, ${ }^{1}$ in the replacement of the father with Bill (and Harold), and in transference and displacement between Agnes and the doctors. Agnes's sexuality is central to Denzin's analysis.

'An entire paper could be devoted to how genital surgery is discussed. Denzin's emphasis on Agnes's castration reflects his psychoanalytic reading. However, this term suggests a lack of respect for Agnes's adamant self-identification as a girl. Agnes prefers the term "corrective surgery," supporting her position that her original sex organs were a mistake that needed to be set right. This position can be contrasted with "sex reassignment surgery" which suggests that the individual is a different sex prior to surgery. 
Denzin's textual production of Agnes begs for its own deconstruction (which, to his credit, he acknowledges in a footnote). Denzin recognizes and deconstructs the imaginary separation between author, text, and subject which foregrounds authorial investments, but he overlays this analysis with his own presumptuous, nonreflexive interpretation of Garfinkel's text, including an authoritative, highly sexualized description of Agnes. Further, he discusses the constructed nature of texts, but demonstrates an ongoing concern with apprehending Agnes's 'real' story, pointing out her 'lies' and questioning Garfinkel's acceptance of Agnes's self-presentation.

In contrast, Mary Rogers reads Garfinkel's essay through a feminist lens that foregrounds the unequal relationship between Garfinkel and Agnes. Rogers sees Agnes as a young, working-class woman who had to participate in Garfinkel's research to get surgery, whereas Garfinkel was not only a professional, but an older male who had the authority to grant or to deny Agnes her operation. Garfinkel barely recognizes these differences. Further, Rogers charges that Garfinkel should be more aware of his own masculine phallocentrism (particularly as he tries to present himself as objective). Garfinkel fails to consider the importance of other women in Agnes's life. He does not express any concern about Agnes's turbulent relationship with her boyfriend. He places great emphasis on Agnes's presentation as a 'stereotypically attractive' woman. Finally, he suggests that Agnes must have gotten sexual pleasure from her penis. In sum, Rogers concludes that "Instead of consistently lifting gender beyond the commonsense understandings that produce it in everyday life, [Garfinkel's work on Agnes] often reproduces that production" (Rogers 187). Again, Agnes remains unusual, while Garfinkel passes for normal.

Rogers is one of the few authors who discusses Agnes with an eye to how power relations affect both her relations to Garfinkel and, more broadly, her day-to-day life. Clearly not all feminists have been so sympathetic to transsexual experiences. For example, Janice Raymond has been strongly criticized within the transsexual community (Califia; Stone) for asserting that transsexuals are not real, but artifical constructions that threaten women. Raymond focuses on "male-to-constructed-females" and identifies transsexuality as part of a patriarchal plot wherein "men [are] wanting to possess females' creative energies" (Califia 94). Clearly, Rogers and Raymond present 
very different kinds of feminism. Rogers's provides an insightful analysis of Garfinkel's patriarchal assumptions and of the gender relations within Agnes's narrative. However, in the context of this particular essay, I wish to draw attention to Rogers's reading of Agnes as yet another interpretation - a feminist one - of Agnes's life. For example, Rogers foregrounds Agnes's social conditions, her relation to the researchers, and her relations to women. She believes that Agnes lacks "a strong 'status shield," (173) and has "maternal support and fast friendships among women" (175). She interprets Bill as "a difficult presence in Agnes's life" (177). Rogers's interpretation of Agnes's story, like my interpretation, is one more interested application of Agnes.

\section{What about Agnes?}

There are multiple stories of Agnes, and Agnes's representations inevitably stand in for her in their multiple forms. Certainly the conditions and concerns of transsexuals should be studied and such studies will always come with investments. Yet the methods used, the intent of such studies, and the everyday material and discursive conditions of the lives of transsexuals require attention.

Some researchers and activists may suggest that to study transsexualism properly, one must be a transsexual (Rubin). I disagree. In fact, I suggest that assuming respect and self-reflexivity from an 'insider' is naive, in that it privileges and homogenizes one shared identity position. Other identity positions (e.g., class, race, religion, personal history, etc.) and different experiences of transsexuality may shatter assumptions of shared understanding. Further, transsexuals are not immune to 'othering,' and there is no reason to assume they should be. Certainly, the conditions and concerns of transsexuals should be studied. It is the methods used and the intent of such studies that require attention. Ethical self-reflexivity - not insider status - is the relevant precursor to research. If transsexuality is to be studied, it must be with attention to the social needs of transsexuals and the everyday material and discursive conditions of their lives (Namaste 1996).

I touch here on the work by Kessler and McKenna, who, like Garfinkel, consider transsexualism to "illuminate ... the day-to-day social construction of gender by all persons" (Kessler \& McKenna 112). Yet, these researchers do not only focus on transsexuality. They 
employ innovative research, such as a gender game, to demonstrate how everyone ascribes gender, and how it is done in a way that privileges certain gender markers (specifically the penis) over others.

Kessler and McKenna consider transsexuality as fashioned to fit into the 'natural attitude' or commonsense assumptions about gender. This natural attitude permeates medical, legal, and popular discourses, which shape how a transsexual must present him- or herself. Kessler and McKenna posit, in fact, that most 'gender work' is done by those perceiving gender, rather than those displaying it. Perceivers hold the natural attitude and filter behavior through the initial assigned gender. Henry Rubin has interpreted Kessler and McKenna as being critical of transsexuals for being "misguided and ill-informed" in their reaffirmation of the 'natural attitude'. He also claims that they believe transsexual experience to "lack a proper degree of feminist political awareness" (272). I disagree, for Kessler and McKenna broaden the range of 'gender dupes' considerably by showing how all people are embedded in the social. In direct contrast, to hold transsexuals like Agnes responsible for gender, as Hausman does, is much more troubling since this amounts to misdirected scapegoating. ${ }^{2}$

Finally, if social scientists are going to study the lives of transsexuals, attention needs to be paid to the lived experiences and material conditions of their subjects in a dichotomously gendered culture that is often hostile and discriminatory toward those who are ambiguously gendered. Namaste (1996) wonders why queer theorists ignore the daily realities of transsexuals' lives. I argue that the same can be asked of sociological research. Gender-bashing and transphobia are rarely discussed, nor are the economic and personal consequences of such discrimination. Instead, transsexuals and other so-called 'deviants' are often exoticized and 'othered' through academic texts that are privileged in knowledge production. Rather than reproducing this framing of transsexuality, and using it as a lens for understanding the nonmarginal, activist researchers must disrupt these assumptions of 'normal' and 'deviant'.

In this paper I have questioned the construction of Agnes. In

${ }^{2}$ Kessler and McKenna also devote an appendix to "Rachel," a male-to-female transsexual, reproducing letters that she wrote to the researchers. Here we have access both to Rachel's self-expression and to how it is interpreted by Kessler and McKenna, thus opening up the interpretive process to readers. 
particular, I have used Agnes as a lens through which we can contemplate both the process of 'othering' and the act of selfreflexivity within sociological theorizing. This paper is framed through my selective reading of the texts, one that focuses more on the examples used than the theories illustrated, for the way in which examples are framed is integral to the ethical and political implications of our theorizing.

Many thanks to the following individuals for their generous comments on various drafts of this paper: Kathryn Payne, Nancy Cook, Beth Jackson, Sheila Cavanagh, Lorna Weir, Trish Salah, Susan Goldberg, Rachel Nash, and Rob Gill.

\section{Works Cited}

Anderson, Karen. Sociology: A Critical Introduction. Toronto: Nelson, 1996.

Atkinson, Jane Monnig. “Anthropology: A Review Essay.” Signs 8 (1982): 236-58.

Bolin, Anne. "Transsexualism and the Limits of Traditional Analysis." American Behavioral Scientist 31 (1987): 41-65.

Califia, Pat. Sex Changes: The Politics of Transgenderism. San Francisco: Cleis, 1997.

Denzin, Norman. "Harold and Agnes: A Feminist Narrative Undoing." Sociological Theory 8 (1990): 198-216.

di Leonardo, Micaela, ed. Gender at the Crossroads of Knowledge: Feminist Anthropology in the Postmodern Era. Berkeley: University of California Press, 1991.

Garfinkel, Harold. Studies in Ethnomethodology. New Jersey: Prentice-Hall, 1967.

Goffman, Erving. Stigma: Notes on the Management of Spoiled Identity. Englewood Cliffs: Prentice-Hall, 1963.

Hale, C. Jacob. "Tracing a Ghostly Memory in My Throat: Reflections on FTM Feminist Voice and Agency." Men Doing Feminism. Ed. Tom Digby. London: Routledge, 1998. 99-131.

Hausman, Bernice. Changing Sex: Transsexualism, Technology, and the Idea of Gender. Durham: Duke University Press, 1995. 
Hilbert, Richard. "Norman and Sigmund: Comment on Denzin's 'Harold and Agnes'.' Sociological Theory 9 (1991): 264-68.

Kessler, Suzanne, and Wendy McKenna. Gender: An Ethnomethodological Approach. New York: Wiley, 1978.

Liazos, Alexander. "The Poverty of the Sociology of Deviance: Nuts, Sluts and Preverts." Social Problems 20 (1972): 103-20.

Mason-Schrock, Douglas. "Transsexuals' Narrative Construction of the 'True Self'.' Social Psychology Quarterly 59 (1996): 17692.

Mead, Margaret. Coming of Age in Samoa: A Psychological Study of Primitive Youth for Western Civilization. New York: Morrow, 1928.

Merton, Robert K. "Social Structure and Anomie." American Sociological Review 3 (1938): 672-82.

Morris, Rosalind C. “'All Made Up': Performance Theory and the New Anthropology of Sex and Gender." Annual Review of Anthropology 24 (1995): 567-92.

Namaste, Ki. “'Tragic Misreadings': Queer Theory's Erasure of Transgender Subjectivity." Queer Studies: A Lesbian, Gay, Bisexual and Transgender Anthology. Ed. Brett Beemyn and Mickey Eliason. New York: New York University Press, 1996. 183-203.

Prosser, Jay. Second Skins: The Body Narratives of Transsexuality.

New York: Columbia University Press, 1998.

Raymond, Janice. The Transsexual Empire. Boston: Beacon, 1979. Rogers, Mary. "They All Were Passing." Gender and Society 6 (1992): 169-91.

Rubin, Gayle. "The Traffic in Women: Notes on the 'Political Economy' of Sex." Towards an Anthropology of Women. Ed. Rayna Reiter. New York: Monthly Review, 1975. 157210.

Rubington, E., and Martha S. Weinberg, eds. Deviance: The Interactionist Perspective. Boston: Allyn and Bacon, 1996. Schissel, Bernard, and Linda Mahood, eds. Social Control in

Canada: Issues in the Social Construction of Deviance. Toronto: Oxford University Press, 1996.

Stone, Sandy. "The Empire Strikes Back: A Post-transsexual Manifesto." Body Guards: The Cultural Politics of Gender Ambiguity. Ed. Julia Epstein and Kristina Staub. New York: 
Routledge, 1991. 280-304.

Strathern, Marilyn. "Gender: Division or Comparison?" Practicing Feminism: Identity, Difference, Power. Ed. Nick Charles and Felicia Hughes-Freeland. London: Routledge, 1994. 38-60.

West, Candace, and Don Zimmerman. "Doing Gender." Gender and Society 1 (1987): 125-51. 